\title{
Synthesis of Azobenzene-Based Ion-Imprinted Polymers for Selective Removal of Cobalt and Copper lons from a Mixture of Metal lons
}

\author{
Tapan Kumar Biswas, ${ }^{a}$ Mashitah Mohd Yusoff, ${ }^{a}$ Mohd Sani Sarjadi, ${ }^{b}$ Sazmal E, Arshad, ${ }^{b}$ \\ Baba Musta, ${ }^{b}$ and Md Lutfor Rahman*,b \\ ${ }^{a}$ FIST, University Malaysia Pahang, 26300 Gambang, Kuantan, Pahang, Malaysia \\ ${ }^{b}$ FSSA, University Malaysia Sabah, UMS Road, 88400 Kota Kinabalu, Sabah, Malaysia
}

Email: lutfor73@gmail.com (M. L. R.)

\begin{abstract}
Azobenzene based metal ion-imprinted polymers (IIPs) were synthesized for selective separation of $\mathrm{Co}(\mathrm{II})$ and $\mathrm{Cu}(\mathrm{II})$ ions from the mixture of metal ions. After polymerization, cavities for the $\mathrm{Co}^{2+}$ and $\mathrm{Cu}^{2+}$ ions were created in the polymer materials by leaching with hydrochloric acid solution. The synthesized IIPs were characterized by FT-IR, ${ }^{1} \mathrm{H}$ NMR and elemental analysis. The competitive sorption studies were carried out to evaluate the selectivity of the target metal ions. Interestingly, the observed sorption capacity was $\mathrm{pH}$ dependent and maximum sorption was found to be 95.4 and $103.0 \mathrm{mg} \cdot \mathrm{g}^{-1}$ for Co-IIPs and Cu-IIPs at $\mathrm{pH} 5$, respectively. It was observed that the IIPs showed good selectivity to $\mathrm{Co}(\mathrm{II})$ and $\mathrm{Cu}(\mathrm{II})$ ions in the presence of other bi and trivalent metal ions in solution. Reused capacity was also checked for six times without a significant decrease in binding affinity for IIPs.
\end{abstract}

Keywords azobenzene, adsorption, ion imprinted polymers, selectivity, cobalt ion, copper ion, removal

\section{Introduction}

Due to high capability of molecular recognition, molecular imprinting technique is used widely for preparation of polymeric materials. Since molecular imprinting exhibits the shape and chemical memory of target molecules, molecular imprinted polymers (MIPs) are synthesized and reported. The formation of specific binding sites for a predetermined ligand is the essence of this method. During the polymerization, the "imprinting molecule" known as a template shows a significant role in the preparation of MIPs. Firstly, functional monomers and templates formed complexes in solution and a high degree of cross-linking agents will be fixed through polymerization. ${ }^{[1-7]} \mathrm{A}$ molecular memory is introduced into the polymer in this way, which is called as molecular imprinting polymer with high capability and specificity of rebinding the analyte. ${ }^{[8-11]}$

Ion-imprinted polymers (IIPs) are also very similar to MIPs, but they can detect the metal ions after imprinted maintaining all attributes of molecular imprinting polymers. The selectivity of the polymeric adsorbent in this IIPs process is based on the ligand specificity, on the coordination number and coordination geometry of the ions and also on the ions charges and size..$^{[12-14]}$ Being outstanding advantages such as simple, convenient to prepare, high selectivity, IIP is used to selectivity of metal ions. One of the most important synthetic methods of IIP is surface ion imprinted technique. ${ }^{[12,15]}$

For example, copper is a very important metal for industries, as well as biological essential element for human health. Furthermore, $\mathrm{Cu}$ (II) ion is also one of the major components of environmental pollution due to heavy metal ions such as $\mathrm{Hg}, \mathrm{Cd}$ $\mathrm{Cr}, \mathrm{Pb}$, etc. ${ }^{[16,17]} \mathrm{A}$ new $\mathrm{Pb}^{2+}$-IIPs was reported based on the dual functional monomers of methacrylic acid and vinyl pyridine for selective solid-phase extraction (SPE) of $\mathrm{Pb}^{2+}$ in water samples. The IIPS-SPE demonstrated potential applications for rapid and high-effective clean-up and enrichment of trace $\mathrm{Pb}^{2+}$ ions in complicated matrices. ${ }^{[18]}$ Among many treatment technologies, adsorption is a popular technology due to sim- plicity. It is employed to mitigate the $\mathrm{Cu}(\mathrm{II})$ smeary problem with low cost and time-saving. ${ }^{[19]}$ Several works have been reported about adsorption of $\mathrm{Cu}(\mathrm{II})$, but the selectivity of adsorbents in application still needs to be improved. ${ }^{[20,21]}$

As a part of vitamin B12, cobalt is an essential element for human health. Among heavy metals, cobalt is an oligo element. However, high concentrations of cobalt in human body may cause low blood pressure, diarrhoea, lung irritation, paralysis, and bone defects. ${ }^{[22]}$ Various methods such as adsorption, ${ }^{[23,24]}$ ion-exchange, ${ }^{[25]}$ extraction, ${ }^{[26,27]}$ membrane filtration ${ }^{[28]}$ and biological treatment ${ }^{[29]}$ have been used for $\mathrm{Co}(\mathrm{II})$ removal. Ion imprinting technology is an effective approach to preparation of imprinted adsorbents for dramatically enhancing binding and selectivity of ion or molecule and reused for many times. ${ }^{[19-22]}$

Based on the literature review, we find that liquid-liquid extraction, co-precipitation and ion-exchange are the common and traditional methods for separation of $\mathrm{Co}$ and $\mathrm{Cu}$. However, these methods often need large amounts of highly pure organic solvents, which are harmful to health and to be created environmental problems. Among them, SPE has paid an increasing attention in the separation of trace level of metal ions. In this point of view, reasonable and promising sorbents development is important based on new SPE is for accurate, rapid and quantitative measurement of trace metal. SPE offers several advantages such as SPE does not have the concerns with emulsion formation, it is less labor intensive, which can be attributed to the mechanism of the technique that allows the compound of interest to be extracted from the sample in a single loading step. Furthermore, SPE is more easily automated, which increases the potential to nearly eliminate manual labor. Finally, SPE is better suited to enriching the concentration of the target compounds in a given sample. However, IIPs are more selective than others due to it prepare by imprinted with desired ion or molecule.

In this current work, we have synthesized two novel IIPs such as Co-IIP and Cu-IIP containing azobenzene chromo- 
phore as a chelate and methacrylic acid as functional monomers. A novel IIP is used for selective identification of $\mathrm{Co}$ and $\mathrm{Cu}$ from other transition and rare earth cations $\left(\mathrm{Ni}^{2+}, \mathrm{Zn}^{2+}, \mathrm{Cd}^{2+}\right.$, $\mathrm{La}^{3+}, \mathrm{Ce}^{3+}$ and $\mathrm{Pr}^{3+}$, etc.) in divalent and trivalent solution mixture.

\section{Experimental}

\section{Materials}

4-Aminobenzoic acid (Fluka, Switzerland), sodium nitrite $(\mathrm{BDH})$, phenol (Merck), acrylic acid, benzoyl peroxide, acetic acid, sodium hydroxide (Aldrich), hydrochloric acid, tetrahydrofuran (THF), ethylene glycol-dimethyl acrylate (EGDMA), benzyl peroxide (BPO), cobalt(II) chloride (Sigma-Aldrich), $\mathrm{Cu}(\mathrm{II})$ acetate (Sigma), nickel(II) chloride (Sigma-Aldrich), zinc(II) sulfate (BDH), cadmium(II) chloride (Aldrich), lanthanum(III) chloride (Sigma-Aldrich), cerium(III) chloride (Aldrich), and praseodymium(III) chloride (Sigma-Aldrich) were used as received. 1,3-Dicyclohexylcarbodiimide (DCC) (Fluka) and 4-(N,N-dimethylamino) pyridine (DMAP) (Fluka) were also used to progress the synthetic work. THF and dichloromethane were refluxed over calcium hydride (Fluka) and phosphorus pentaoxide, respectively. The solvent was distilled out before use. Without further purification, the other solvents and chemicals were used as received.

\section{Instruments}

Perkin Elmer (670) spectrometer was used to record the FTIR spectra. ${ }^{1} \mathrm{H}$ NMR $(500 \mathrm{MHz})$ spectra were measured with a Bruker (DMX500) spectrometer. The morphology and composition of compounds (elements detection) were studied by field emission scanning microscopy (FESEM) and FESEM-EDX (JSM-7800F, FESEM, JEOL, USA), respectively. FE-SEM measurement was performed to study the morphology of IIPS. Sputter coating was applied for an ultra-thin coating of platinum metal onto a specimen. The absorbance measurements were performed by UV-vis spectrophotometer (UV-2600 Shimadzu). Metal ion concentrations were analyzed by ICP-MS (Agilent 7500 series). An Agilent (7500) instrument was used with the operating conditions: plasma gas flow rate $15 \mathrm{~L} \cdot \mathrm{min}^{-1}$, auxiliary gas flow rate $1.0 \mathrm{~L} \cdot \mathrm{min}^{-1}$, cooling water flow rate (RF/TP) 2.0 $\mathrm{L} \cdot \mathrm{min}^{-1}$, ICP RF Power $1200 \mathrm{~W}$, Interface pressure $350 \mathrm{~Pa}$, Cooling water flow rate (WC/IF) $1.8 \mathrm{~L} \cdot \mathrm{min}^{-1}$ and analyzer pressure $3 \times 10^{-4} \mathrm{~Pa}$ (no gas mode).

\section{4-[(E)-(4-hydroxyphenyl)diazenyl]benzoic acid (1)}

The azo-based polymers compounds were synthesized as outlined in Scheme 1. 4-Aminbenzoic acid (2 g, $0.0182 \mathrm{~mol})$ was placed into a $250 \mathrm{~mL}$ beaker and dissolved in a mixture of $100 \mathrm{~mL}$ of methanol and water (5:1 ratio). About $5 \mathrm{~mL}$ of hydrochloric acid $(37 \%)$ was added and it was cooled to $2{ }^{\circ} \mathrm{C}$ with an ice bath. An aqueous solution of sodium nitrite (1.5 equivalents, $1.89 \mathrm{~g}$ in $10 \mathrm{~mL}$ ) was added drop-wise and the mixture was stirred for $1 \mathrm{~h}$. The mixture was transferred into $400 \mathrm{~mL}$ of $\mathrm{MeOH}$ with $100 \mathrm{~mL}$ distilled water (temp. maintained at $2{ }^{\circ} \mathrm{C}$ by ice bath) containing the phenol (1 equivalent, $1.717 \mathrm{~g}$ ) and $\mathrm{pH} 9$ was adjusted using $10 \%$ sodium hydroxide solution, which was further stirred for $4 \mathrm{~h}$. Then, the mixture was poured in a beaker containing $800 \mathrm{~mL}$ water and the $\mathrm{pH}$ of the mixture was adjusted around 3 using $\mathrm{HCl}(10 \%)$. The resulting precipitate was collected by filtration. The product compound 1 was recrystallized twice using methanol to give a reddish colored solid with a yield of $68 \%$. IR $(\mathrm{KBr}) v_{\max }: 3429(\mathrm{O}-\mathrm{H}$ stretch), 3283 (aromatic $\mathrm{C}-\mathrm{H}$ stretch), 1681 ( $\mathrm{C}=\mathrm{O}$ stretch, acid), 1585 (aromatic $\mathrm{C}=\mathrm{C}$ stretch), $1458\left(\mathrm{~N}=\mathrm{N}\right.$ stretch), $1282\left(\mathrm{C}-\mathrm{O}\right.$ stretch $\mathrm{cm}^{-1}$. ${ }^{1} \mathrm{H} \mathrm{NMR}\left(\mathrm{CDCl}_{3}, \mathrm{Me}_{4} \mathrm{Si}, 500 \mathrm{MHz}\right) \delta: 8.46$ (dd, $\left.4 \mathrm{H}, \mathrm{Ar}-\mathrm{H}\right), 8.08$ (d, 2H, Ar-H), 7.97 (d, 2H, Ar-H), 9.40 (s, 1H, Ar-OH).
Scheme 1 General synthesis scheme of Co-IIPs and Cu-IIPs
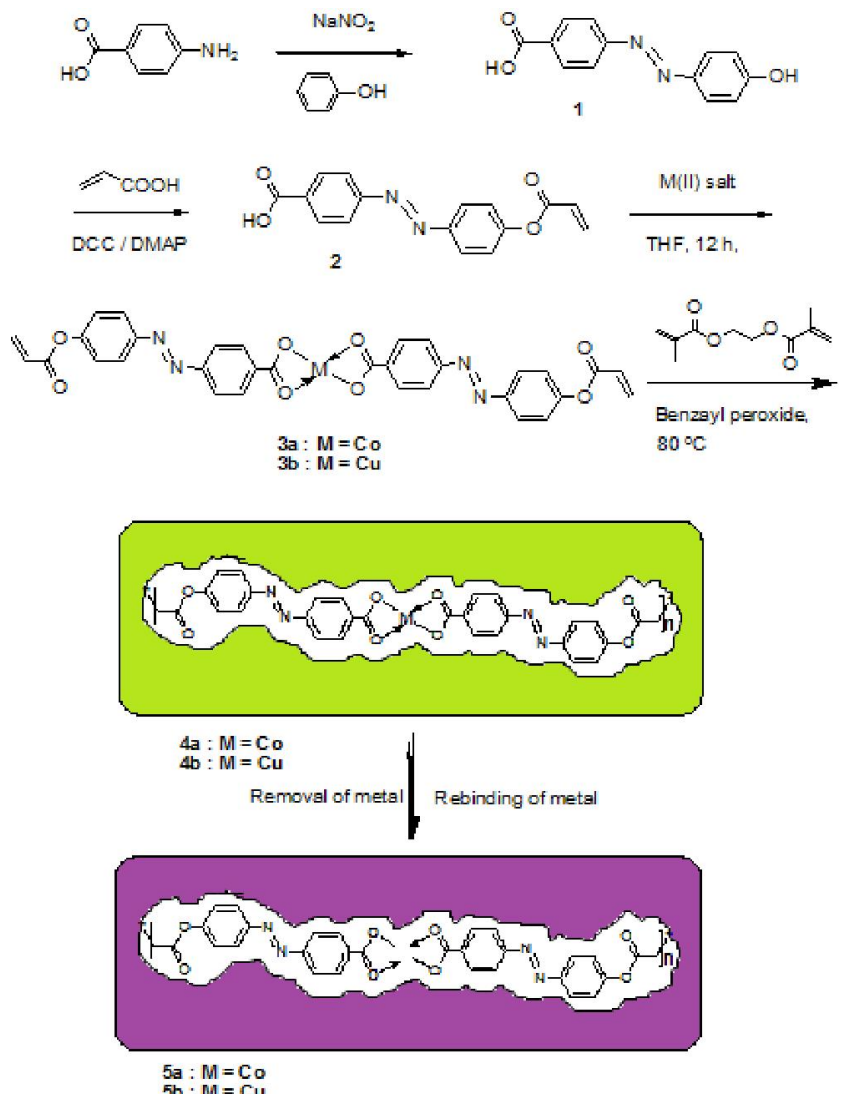

$5 \mathrm{a}: \mathrm{M}=\mathrm{Co}$
$5 \mathrm{~b}: \mathrm{M}=\mathrm{Cu}$

4-\{(E)-[4-(acryloyloxy)phenyl]diazenyl\}benzoic acid (2)

In a round bottom flask, $250 \mathrm{mg}$ of compound $1(1.033 \mathrm{mmol})$ was dissolved with dry THF $(5 \mathrm{~mL})$ and dry $\mathrm{CH}_{2} \mathrm{Cl}_{2}(20 \mathrm{~mL})$ with stirring. Then 1.2 equivalents $(89 \mathrm{mg})$ of acrylic acid, 1.5 equivalents $(319 \mathrm{mg}$ ) of DCC and $10 \mathrm{mg}$ of DMAP were added and stirred continuously. The progress of the reaction was monitoring with thin layer chromatography-silica gel plate (hexane and ethyl acetate ratio is $2: 1$ ). After stirrer for $24 \mathrm{~h}$, the product was extracted with $\mathrm{CH}_{2} \mathrm{Cl}_{2}$ with few drops of acetic acid and water and the product was washed with water at least three times. The solvent was removed by rotary evaporator and solid was dried in oven at $50{ }^{\circ} \mathrm{C}$. Reddish yellow colour compound 2 (yield 58\%) was obtained.

\section{Preparation of metal ion complexes}

4-\{(E)-[4-(acryloyloxy)phenyl]diazenyl\}benzoic acid-cobalt (3a) or 4-\{(E)-[4-(acryloyloxy)phenyl]diazenyl\}benzoic acidcopper (3b)

Briefly, in a $50 \mathrm{~mL}$ round bottom flask, $50 \mathrm{mg}(0.176 \mathrm{mmol})$ of compound 2 was dissolved with anhydrous THF $(10 \mathrm{~mL})$ and then treated with 1 equivalent of metal salt $\mathrm{Co}$ (II) chloride or $\mathrm{Cu}$ (II) nitrate, as imprint metal ions, used separately at room temperature under continuous stirring for $12 \mathrm{~h}$. At the end of this process, different color complexes were appeared (3a and 3b)

Synthesis of $\mathrm{Co}$ (II) or $\mathrm{Cu}$ (II) ion-imprinted polymer (4a and 4b)

The thermal polymerization technique was used to prepare the azo based imprinted polymers. The syntheses procedure of the Co-IIP and Cu-IIP preparation are illustrated in Scheme 1. After complexation (3a or $\mathbf{3 b}$ ), THF containing $\mathbf{3 a}$ or $\mathbf{3 b}$ was added to a mixture of cross-linking agent EGDMA $(1.0 \mathrm{~g})$, benzoyl peroxide $(40 \mathrm{mg})$ as an initiator and purge $\mathrm{N}_{2}$ gas for $20 \mathrm{~min}$ to remove molecular $\mathrm{O}_{2}$, which traps the radicals and 
retards the polymerization. Using high vacuum to remove $\mathrm{O}_{2}$, the flask was set up on an oil bath and heated continuously $80{ }^{\circ} \mathrm{C}$ for $24 \mathrm{~h}$ under magnetic stirring to complete the polymerization. After polymerization, the products are precipitated in methanol and dried properly in an oven about $50{ }^{\circ} \mathrm{C}$ until constant weight. After polymerization, the imprinted ions $\mathbf{4 a}$ and $\mathbf{4 b}$ were leached with $20 \mathrm{~mL} \mathrm{HCl}$ through shaking from the above synthesized polymer materials and formed compounds $\mathbf{5 a}$ and $\mathbf{5 b}$.

\section{Adsorption-desorption of azo-based ion imprinted poly- mer}

Batch experiments were applied to study the sorption and desorption of $\mathrm{Co}^{2+}$ and $\mathrm{Cu}^{2+}$ for azo-based ion imprinted polymer (M-IIPs) materials in aqueous solutions.

\section{General procedure of batch adsorption}

Exactly $100 \mathrm{mg}$ of the imprinted polymers (5a or $\mathbf{5 b}$ in Scheme 1) was placed in a plastic container and then single metal ion solution of $20 \mathrm{~mL}(0.1 \mathrm{M})$ was added into $\mathbf{5 a}$ or $\mathbf{5 b}$ to appropriate $\mathrm{pH}(3-8)$ using sodium acetate buffer $(20 \mathrm{~mL})$ and shaking $3 \mathrm{~h}$ with speed of $200 \mathrm{rpm}$ with a shaker. After reaching equilibrium, the polymeric ligand was removed by filtration and metal ions concentration was determined by ICP-OES. Perkin Elmer, optima 8300 , ICP-OES tool was used for the measurements.

\section{Adsorption-desorption on the IIPs}

For this experiment, an aliquot of cobalt or copper solution (e.g., $20 \mathrm{~mL}$ of $50 \mathrm{mg} \cdot \mathrm{L}^{-1}$ ) was treated with $50.0 \mathrm{mg}$ of IIPs at $\mathrm{pH} 3-8$. The suspension was stirred for $6 \mathrm{~h}$ using a magnetic stirrer. The supernatant solution was collected by filtration and the $\mathrm{Co}^{2+}$ or $\mathrm{Cu}^{2+}$ ion pre-concentrated onto IIPs materials were then eluted by $20 \mathrm{~mL}$ of $2 \mathrm{M} \mathrm{HCl}$ in water during $12 \mathrm{~h}$ stirring. The suspensions were centrifuged and then eluent solutions containing $\mathrm{Co}^{2+}$ or $\mathrm{Cu}^{2+}$ ion were removed from the IIPs. The resulted $\mathrm{Co}^{2+}$ or $\mathrm{Cu}^{2+}$ ion contents of the solutions were determined by ICP-MS. Using Eq. (1), the percentage of metal ion adsorbed on the sorbent was determined, where $C_{\mathrm{i}}$ and $C_{\mathrm{f}}$ $\left(\mathrm{mg} \cdot \mathrm{L}^{-1}\right)$ are the concentrations of metal ions before and after extraction.

$$
\operatorname{Extraction}(\%)=\frac{C_{\mathrm{i}}-C_{\mathrm{f}}}{C_{\mathrm{i}}} \times 100
$$

Eq. (2) can be used to calculate the metal ion adsorption.

$$
q_{\mathrm{e}}=\frac{C_{\mathrm{i}}-C_{\mathrm{f}}}{m} \times V
$$

where $q_{\mathrm{e}}$ is the adsorption amount $\left(\mathrm{mg} \cdot \mathrm{g}^{-1}\right), V$ is the volume of metal solution $(\mathrm{L}), m$ is the mass of polymeric ligand $(\mathrm{g})$.

The distribution ratio, $K_{d}\left(\mathrm{~mL} \cdot \mathrm{g}^{-1}\right)$ of metal ions between the M-IIPs and aqueous solution was also calculated by Eq. (3), where $V$ is the volume of solution and $m$ is mass of IIPs $(\mathrm{mg})$.

$$
K_{\mathrm{d}}=\left(\frac{C_{\mathrm{i}}-C_{\mathrm{f}}}{C_{\mathrm{f}}}\right) \frac{V}{m}
$$

Selectivity coefficients $(k)$ for $\mathrm{Co}^{2+}$ or $\mathrm{Cu}^{2+}$ ion relative to foreign ions in the solution are defined as:

$$
K_{\mathrm{Ca}^{2+} \mathrm{M}^{+}}=\frac{K_{\mathrm{d}}^{\mathrm{C}^{2+}}}{K_{\mathrm{d}}^{\mathrm{M}^{+}}}
$$

where, $K_{\mathrm{d}}^{\mathrm{Co}^{2+}}$ and $K_{\mathrm{d}}^{\mathrm{M}^{+}}$are the distribution ratios of $\mathrm{Co}^{2+}$ and foreign metal ions, respectively. Moreover, $K_{\mathrm{d}}^{\mathrm{Cu}^{2+}}$ and $K_{\mathrm{d}}^{\mathrm{M}^{+}}$ were used in Eq. (4) for measuring the selectivity coefficient $(k)$ of $\mathrm{Cu}^{2+}$ ion relative to foreign ions in the solution, respectively.

\section{Results and Discussion}

\section{Synthesis}

An azo compound 4-[(E)-(4-hydroxyphenyl)diazenyl]benzoic acid (1) was synthesized using 4-aminbenzoic acid as a starting material, which is undergone diazotization and coupling reaction with sodium nitrite and phenol under cooled temperature about $2{ }^{\circ} \mathrm{C}$ in acidic medium.

Compound 1 was recrystallized from ethanol, achieving a red color crystalline solid with yield of $68 \%$. Further reaction with acrylic acid produced $4-\{(E)$-[4-(acryloyloxy)phenyl]diazenyl\}benzoic acid 2 by coupling reaction with DCC, $58 \%$ reddish yellow color compound. Then, compound 2 was treated with metal salts of $\mathrm{Co}$ and $\mathrm{Cu}$ ion, as imprint ion ( 2 batch method separately) under maintained continuous stirring at room temperature. Finally, the compounds appeared complex with different colors.

Then, the complex $\mathbf{3 a}$ or $\mathbf{3 b}$ formation was confirmed by using UV-vis spectroscopy technique. Then, thermal polymerization technique was use to synthesize the metal ions imprinted polymers (IIPs), which are referred to azoacid-based metal complex. EGDMA was used as a cross-linker agent, and complex solution $\mathbf{3 a}-\mathbf{3 b}$ was added with benzoyl peroxide as an initiator, and the mixture was heated at $80{ }^{\circ} \mathrm{C}$ for $34 \mathrm{~h}$. After polymerization, methanol was used to precipitate the product and the IPs was dried $(\mathbf{4 a}-\mathbf{4 b})$ at $50^{\circ} \mathrm{C}$ with an oven. Then, the cobalt and copper ions were leached from polymer products (IIPs) with $20 \mathrm{~mL} \mathrm{HCl}(2 \mathrm{M})$ solution through shaking for further adsorption of metal ions on the imprinted cavity polymers of $\mathbf{5 a}-\mathbf{5 b}$ separately. The details synthesis strategy of the Co-IIPs and Cu-IIPs preparation is depicted in Scheme 1.

\section{Characterization}

\section{FT-IR spectra}

The FT-IR spectra of azoacid-acrylate compound (2), azoacid-acrylate-Co-IIPs (4a) and azoacid-acrylate-Co-IIPs (5a) (leached) were obtained by using a $\mathrm{KBr}$ pellet method in Figure 1a. The similar IR spectra have been observed for the compounds of Cu-IIPs (4b) and Cu-IIPs (5b) (leached), but they have high intensity spectra. The backbone structures of all polymers are similar, so the similar characteristic peaks in IR spectra were observed. Those functional groups belong to polymers. For compound 2, the $\mathrm{O}-\mathrm{H}$ stretching and bending vibrations of carboxyl groups are located at 3440, 3336 and $1389 \mathrm{~cm}^{-1}$, respectively. In addition, stretching vibrations of $\mathrm{CH}_{2}$ groups are 2955 and $2818 \mathrm{~cm}^{-1}$. The typical vibration absorptions are 1675 and $1630 \mathrm{~cm}^{-1}$ for carbonyl and vinyl functional group of acid compound 2. Moreover, the typical vibration absorption of benzene ring corresponds to 1581 and $1420 \mathrm{~cm}^{-1}$ Representative vibration of 1245 and $1150 \mathrm{~cm}^{-1}$ of the aryl ring-O vibration and phenyl- $\mathrm{N}$ stretching mode were clearly observed in the FTIR spectra of supported azo-molecule, additional $\mathrm{O}-\mathrm{H}$ bending mode. The stretching vibrations responsible for $\mathrm{C}=\mathrm{O}$ bonds are located at $1727 \mathrm{~cm}^{-1}$ for Co-IIPs (4a) and $1728 \mathrm{~cm}^{-1}$ for $\mathrm{Cu}$-IIPs (4b), whereas asymmetric stretching vibrations of $\mathrm{CH}_{2}$ groups are $2955 \mathrm{~cm}^{-1}$. ${ }^{[30,31]}$ Due to polymerization, vinyl functional group at 3111 and $1630 \mathrm{~cm}^{-1}$ are absent in compounds $\mathbf{4 a}$ and $\mathbf{4 b}$. In case of both leached polymers (Co-IIPs and Cu-IIPs), IR spectra are almost similar with corresponding unleached polymers (Co-IIPs and Cu-IIPs) in Figure 1.

\section{Surface morphology analysis using FE-SEM}

The scanning electron microscopy is a suitable tool to observe the structural morphology of IIPs. Field emission scanning electron microscopy (JEOL JSM-7800F) was used to observe the surface morphology of the IIPs. SEM micrographs were taken of samples after extraction of the template molecule to visualize their morphologies. FE-SEM images of Figure $2 a$ 

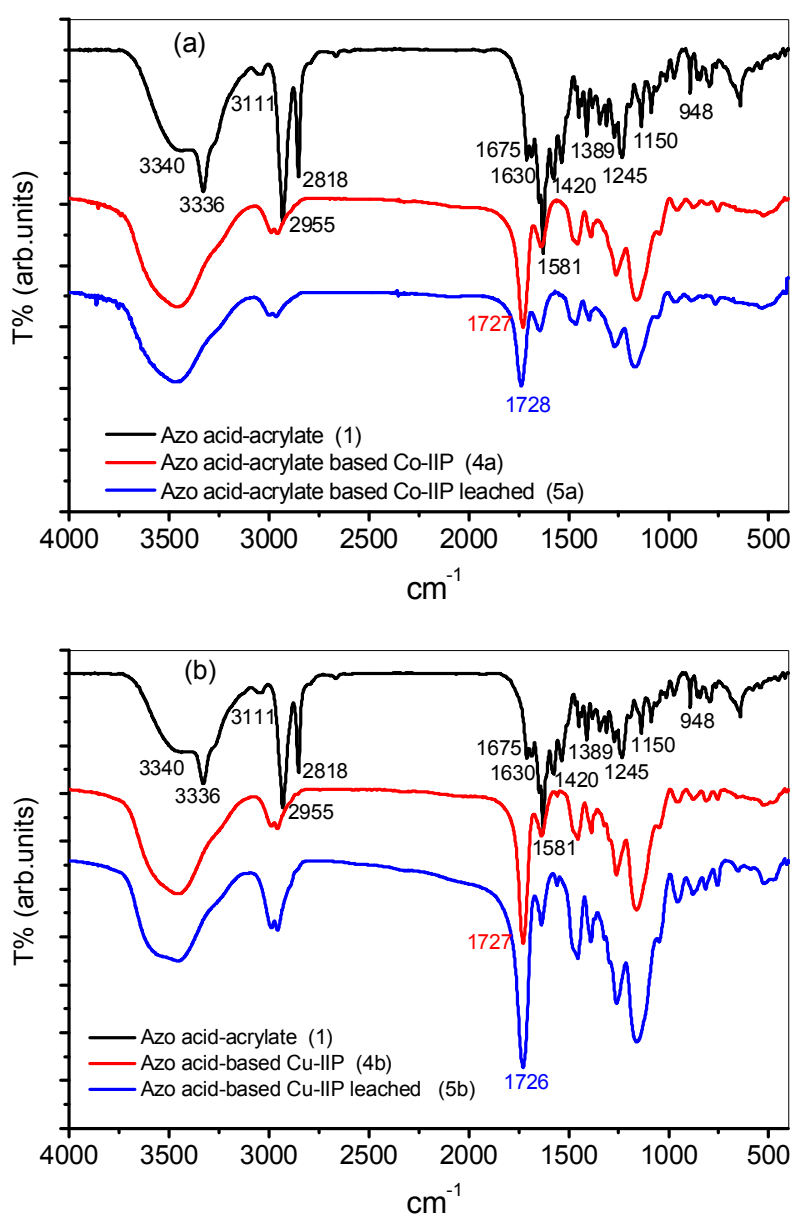

Figure 1 Comparison FTIR spectra for (a) azoacid-acrylate (2), azoacid-acrylate based Co-IIPs (4a) and azoacid-acrylate based Co-IIPs (leached) (5a); (b) azoacid-acrylate (2), azoacid-acrylate based Cu-IIPs (4b) and azoacid-acrylate based Cu-IIPs (leached) (5b).

shows for the synthesized azobenzene-acrylate compound 2 . Figures $2 b$ and $2 c$ image are represented to the Co-IIPs $4 a$ and $\mathrm{Cu}$-IIPs 4b, respectively. An unsmooth surface of the compound (Figure 2a) was observed with an irregular spherical shape. This type of surface nature indicated that the compounds are forming structurally and purely in organic nature. On the other hand, the IIPs (Figures $2 \mathrm{~b}$ and $2 \mathrm{c}$ ) seem to porous microstructure and it was good agreement with other observations. ${ }^{[32]}$

\section{EDX analysis for elemental evaluation}

Electron dispersive X-ray spectroscopy (EDX) investigation was observed to know the quantitative presence of all in the synthesized IIPs samples of $\mathbf{4 a}$ and $\mathbf{4 b}$. Figure $3 \mathbf{a}$ showed that the prepared compound was made up of $\mathrm{C}, \mathrm{N}, \mathrm{O}$, and Co only. Their weight compositions were $38.05 \%, 5.97 \%, 51.23 \%$ and $4.75 \%$ for $\mathrm{C}, \mathrm{N}, \mathrm{O}$, and $\mathrm{Co}$, respectively, which is illustrated in Figure $3 a$ inside the inset. The signals corresponding to $\mathrm{C}, \mathrm{N}, \mathrm{O}$, and Co have been detected and the compound has no other element, meaning that it is purely azo based Co-IIPs. Different observation was found for $\mathrm{Cu}$ (II)-IIPs in Figure $3 \mathrm{~b}$ due to different metals such as copper, which showed that the prepared compound was made up of $\mathrm{C}, \mathrm{N}, \mathrm{O}$, and $\mathrm{Cu}$ only. Their weight compositions were $23.91 \%, 6.26 \%, 36.91 \%$ and $32.92 \%$ for $\mathrm{C}$, $\mathrm{N}, \mathrm{O}$, and $\mathrm{Cu}$, respectively, which is presented in Figure $3 \mathrm{~b}$ inside the inset. It can be concluded that the prepared compound has no other element except purely Cu-IIPs.
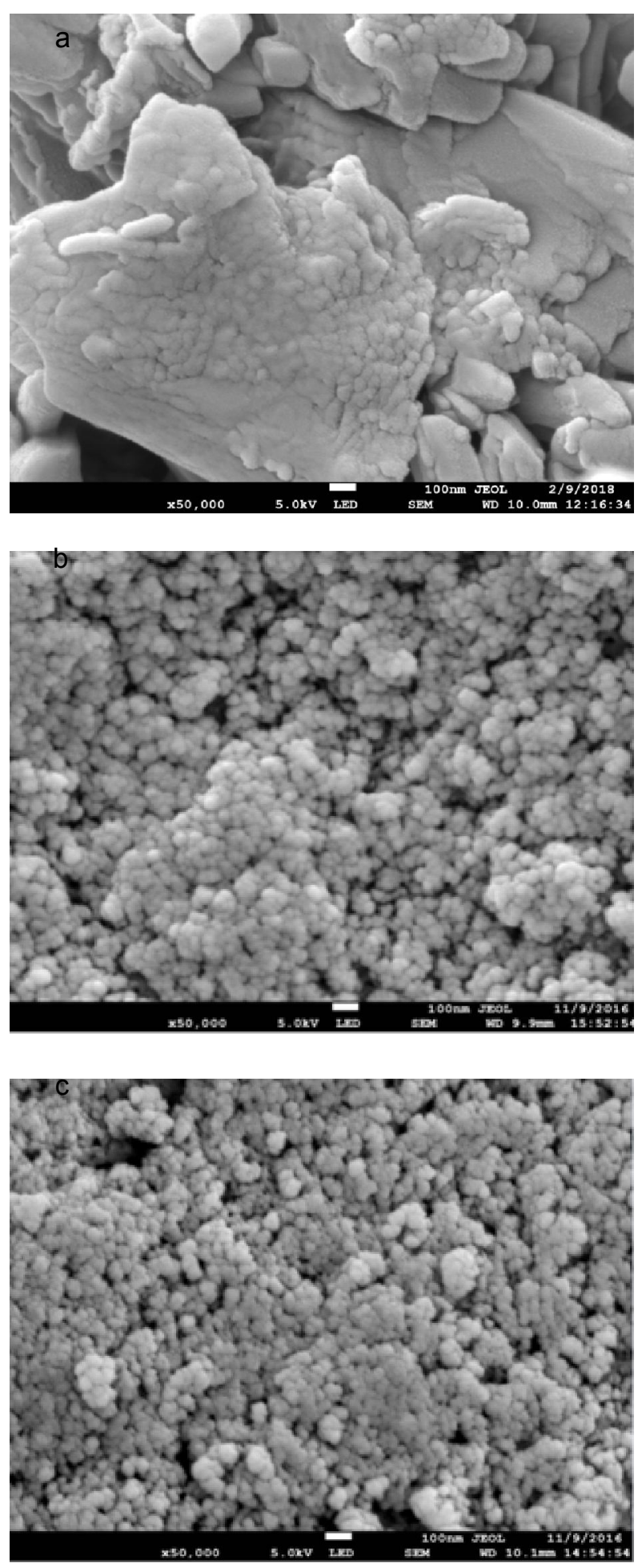

Figure 2 FESEM images of (a) azoacid-acrylic polymer (2); (b) azoacid-acrylic based Co(II)-IIP (4a); (c) azoacid-acrylic based-Cu(II)-IIP (4b). All micrograph's magnification are 50 000 .

\section{Sorption and desorption}

\section{Effect of $\mathrm{pH}$ on the adsorption of metal ions}

To evaluate the sorbent adsorption behavior and check the effect of $\mathrm{pH}$, a series of $\mathrm{pH}$ values ranging from 3 to 8 were used and observed. Herein, $\mathrm{pH}$ was adjusted with the addition of sodium acetate buffer solution. The adsorption capacity 

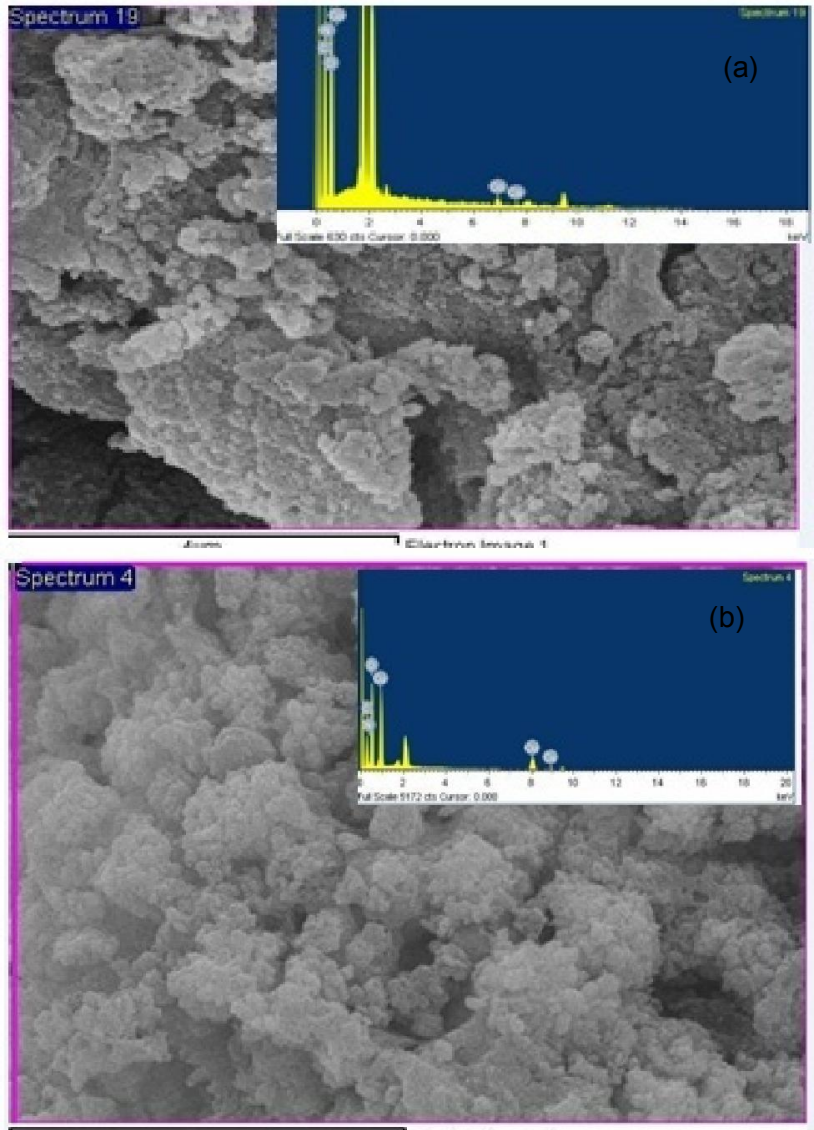

Figure 3 EDX spectra for (a) azo-based Co(II)-IIPs (4a) (before leaching); (b) azo-based Cu(II)-IIPs (4a) (before leaching).

of $\mathrm{Co}$ (II) and $\mathrm{Cu}$ (II) ion on sorbents as a function of $\mathrm{pH}$ is shown in Figure 4. It was found that the adsorption of $\mathrm{Co}$ (II) and $\mathrm{Cu}$ (II) ions onto the $\mathrm{Co}$ and $\mathrm{Cu}$ ion imprinted polymers increases gradually upon increasing the $\mathrm{pH}$ from 3 to 5 . Maximum recoveries of corresponding metal ions were at $\mathrm{pH} 5$ and it was almost saturated over $\mathrm{pH} \mathrm{6,} \mathrm{which} \mathrm{is} \mathrm{representative} \mathrm{in}$ Figure 4. It is noted that there is no precipitate in the sample solution under the studied conditions. Moreover, Table 1 also represents the sorption capacity of the corresponding metal ions imprinted polymers over the studied $\mathrm{pH}$ ranges and showed the good agreement of the $\mathrm{pH}$ dependent ability of the both sorbents. A batch equilibrium method was used to estimate the adsorption behavior of the sorbent/ ligand towards different metals, using the complex form of selected metal ions $\left(\mathrm{Co}^{2+}\right.$ and $\left.\mathrm{Cu}^{2+}\right)$. After batch equilibration, the complex formation of the $\mathrm{COOH}$ group (behave bidentate ligands) with the metal ions resulted in a four member stable ring complex. The metal ions are bound to both oxygen anions and the dative oxygen atoms, and the chelating complex $\mathbf{4 a}$ or $\mathbf{4 b}$ is represented in Scheme 1.

\section{Adsorption capacity}

The total amounts of ion adsorbed per gram of the sorbent materials are known as adsorption capacity $(Q)$. For IIPs, adsorption capacity is an important indicator for the evaluation of the synthesized sorbent. Using the IIPs sorbent per gram can understand the maximum metal ions adsorbed. ${ }^{[33]}$ In order to evaluate the static adsorption capacity of $\mathrm{Co}(\mathrm{II})$ ion onto the $\mathrm{Co}$ (II)-IIP at $25^{\circ} \mathrm{C}, 50 \mathrm{mg}$ of leached IIPs sorbent was equilibrated with $20 \mathrm{~mL}$ of $\mathrm{Co}$ ion solutions possessing the concentration of $50 \mathrm{mg} \cdot \mathrm{L}^{-1}$ at optimal conditions. Same procedure was used to $\mathrm{Cu}$ (II)-IIPs due to evaluate the adsorption capacity of $\mathrm{Cu}$ (II) ion onto the IIPs at the studied conditions. Eq. (2)

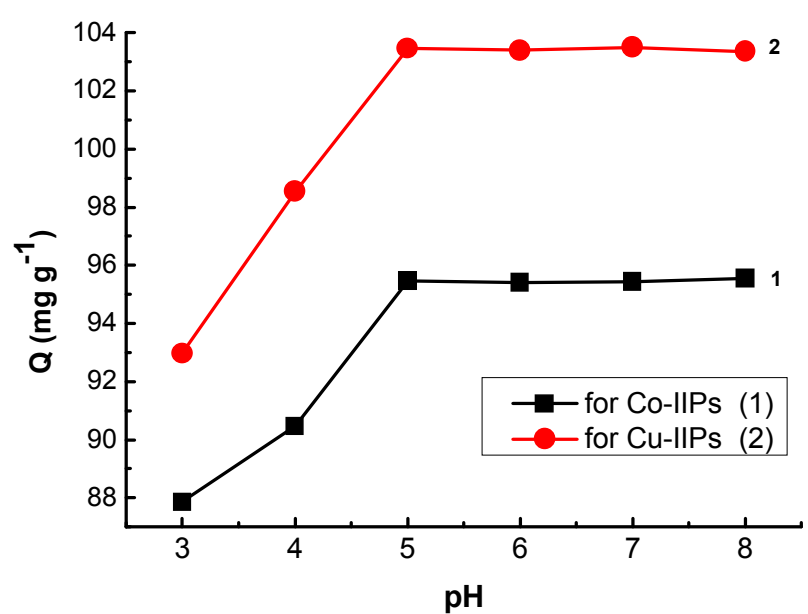

Figure 4 Effect of pH on sorption capacity for Co-IIPs (1) and Cu-IIPs (2).

was used to calculate the adsorption capacity and the calculated values are revealed in Table 1 over the studied $\mathrm{pH}$ ranges. Due to the possibility of precipitation or hydroxide form of metal ions, higher values of $\mathrm{pH}$ were not considered here during the batch experiment. Table 1 represents the values of extraction yield of $\mathrm{Co}^{2+}$ and $\mathrm{Cu}^{2+}$ ions using azo polymers at studied $\mathrm{pH}$. The effect of $\mathrm{pH}$ on the extraction yield (\%) of $\mathrm{Co}^{2+}$ or $\mathrm{Cu}^{2+}$ ions using corresponding Co-IIPs or Cu-IIPs polymers is shown in Figure 5. It can be observed that the percentage of $\mathrm{Co}^{2+}$ or $\mathrm{Cu}^{2+}$ ions adsorption increased at higher $\mathrm{pH}$ values and mostly saturated at $\mathrm{pH} 6$. Those ions $\left(\mathrm{Co}^{2+}\right.$ and $\mathrm{Cu}^{2+}$ ions) are quantitatively high extracted at $\mathrm{pH} 5$. The sorption quantity is a little bit low due to the protonation of the binding sites of polymeric $\mathrm{M}-$ IIPs at the lower $\mathrm{pH}$.

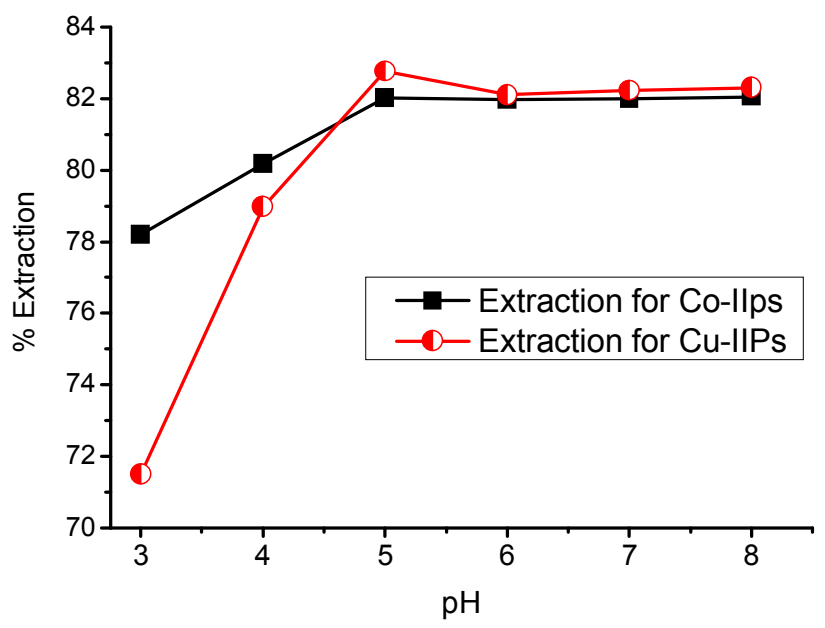

Figure 5 Effect of $\mathrm{pH}$ on the extraction (\%) of $\mathrm{Co}$ and $\mathrm{Cu}$ ions using Co-IIPs and Cu-IIPs.

\section{Selectivity of $\mathrm{Co}^{2+}$ and $\mathrm{Cu}^{2+}$ ions}

To investigate the adsorption specificity of IIPs towards metal ions need to perform the selectivity experiments. The distribution and selectivity coefficients of $\mathrm{Co}^{2+}$ and $\mathrm{Cu}^{2+}$ with respect to other foreign metal ions such as $\mathrm{Ni}^{2+}, \mathrm{Zn}^{2+}, \mathrm{Cd}^{2+}, \mathrm{La}^{3+}$, $\mathrm{Ce}^{3+}$ and $\mathrm{Pr}^{3+}$ can be measured from binding data using Eqs. (3) and (4), respectively. In fact, three main factors are dominated in the selective extraction or separation of a given metal ion in presence of other foreign metal ions. The first one is the nature of ligand donating sites that are capable of selective binding to the central metal ion. The second one is the nature of the 
Table 1 Sorption capacity at different $\mathrm{pH}$ with azo-based IIPs

\begin{tabular}{|c|c|c|c|c|c|c|c|c|}
\hline \multirow[t]{2}{*}{ M-IIP } & \multicolumn{4}{|c|}{ Sorption capacity $\mathrm{Q} /\left(\mathrm{mg} \cdot \mathrm{g}^{-1}\right)$} & \multicolumn{4}{|c|}{ Extraction $(\% E)$} \\
\hline & $\mathrm{pH} 3$ & $\mathrm{pH} 4$ & $\mathrm{pH} 5$ & $\mathrm{pH} 6$ & $\mathrm{pH} 3$ & $\mathrm{pH} 4$ & $\mathrm{pH} 5$ & $\mathrm{pH} 6$ \\
\hline Co-IP & 87.8 & 90.4 & 95.4 & 95.2 & 78.2 & 80.1 & 82.0 & 81.9 \\
\hline Cu-IP & 92.9 & 98.5 & 103 & 103 & 71.5 & 78.9 & 82.7 & 82.1 \\
\hline
\end{tabular}

Table 2 Distribution ratio $\left(K_{d}\right)$ and selectivity coefficient $(k)$ values of specific Co-IIPs and Cu-IIPs at pH 5

\begin{tabular}{|c|c|c|c|c|}
\hline \multirow{2}{*}{ Cation } & \multicolumn{4}{|c|}{$\mathrm{pH} 5$} \\
\hline & $K_{d}$ Co-IIP $\left(\mathrm{mL} \cdot \mathrm{g}^{-1}\right)$ & $K_{d}$ Cu-IIP $\left(\mathrm{mL} \cdot \mathrm{g}^{-1}\right)$ & $k$ Co-IIP & $k \mathrm{Cu}-\mathrm{IIP}$ \\
\hline $\mathrm{Co}^{2+}$ & 91.2 & 17.9 & - & 4.1 \\
\hline $\mathrm{Cu}^{2+}$ & 11.4 & 96.0 & 7.9 & - \\
\hline $\mathrm{Ni}^{3+}$ & 16.8 & 18.2 & 5.4 & 5.2 \\
\hline $\mathrm{Zn}^{2+}$ & 12.8 & 11.6 & 7.0 & 8.2 \\
\hline $\mathrm{Cd}^{2+}$ & 16.1 & 20.2 & 5.6 & 4.7 \\
\hline $\mathrm{La}^{3+}$ & 3.1 & 5.6 & 28.9 & 16.9 \\
\hline $\mathrm{Ce}^{3+}$ & 7.2 & 3.7 & 12.6 & 25.5 \\
\hline $\mathrm{Pr}^{3+}$ & 4.9 & 5.0 & 18.3 & 19.0 \\
\hline
\end{tabular}

metal ion to be selectively extracted. It acts as either a hard or soft acid. The third key factor in selective extraction or separation is hydrogen ion concentration in metal ion solution. ${ }^{[34,35]}$ The obtained results are summarized in Table 2 at $\mathrm{pH} 5$. It is clearly shown that the ion imprinting effect by comparing the obtained selectivity results is tabulated in Table 2 .

Furthermore, the target ions are allowed to selective adsorption due to their cavities as specific holes in imprinted polymers. More specifically, the imprinted polymers with cavities have a definite shape and size of the template. It is difficult to absorb the substances with smaller or bigger size than the imprinted template. Due to molecular geometry, the prepared ion imprinted polymers such as $\mathrm{Co}$ (II)-IIPs and $\mathrm{Cu}$ (II)-IIPs showed excellent selectivity for the target molecules like $\mathrm{Co}$ (II) ions and $\mathrm{Cu}(\mathrm{II})$ ions, respectively. Considering the high selectivity coefficient values obtained by IIPs substances, an important difference between the binding of $\mathrm{Co}^{2+}$ or $\mathrm{Cu}^{2+}$ ions and others competitor ions to the imprinted sorbent can be clearly stated that the synthesized IIPs can be applied as a selective sorbent for recognition or separation of $\mathrm{Co}^{2+}$ and $\mathrm{Cu}^{2+}$ ions in the presence of other metal cations (di- and tri-valent) in various synthetic samples with different and complex matrices.

Zhang et al. ${ }^{[36]}$ synthesized new $\mathrm{Hg}^{2+}$ ion-imprinted polymers (IIPs) by a sol-gel process using the chelating agent dithizone and 3-aminopropyltriethoxysilane as a functional monomer for mercury speciation analysis in environmental and biological samples by solid-phase extraction (SPE) and atomic fluorescence spectroscopy (AFS) detection. A review work is reported on the current status and challenges of ion imprinting described various aspect such as fundamentals of IIPs preparation, principles of IIPs preparation, components of IIPs preparation, functional monomer and ligand, cross-linker, initiator and porogen, preparation technologies of IIPs and also applications of various IIPs. ${ }^{[37]}$ Another review also reported on the molecular imprinting: perspective and applications. The review contains about fundamentals of MIPs, smart MIT for MIPs, ingenious MIT for MIPs, special strategies of MIT for MIPs and also applications of MIPS. ${ }^{[38]}$ A green IIP was reported on the three functional monomers of low-cost eco-friendly gelatin $(G)$, 8-hydroxyquinoline (HQ) and chitosan (C), namely G-HQC IIPs, and were applied as an effective and recyclable adsorbent to remove $\mathrm{Cu}(\mathrm{II})$ from aqueous solution. ${ }^{[39]} \mathrm{A}$ new dummy molecularly imprinted polymer (DMIP) with propanamide as a dummy template molecule was reported for magnetic solid-phase extraction (MSPE) of acrylamide in biscuit samples, followed by high performance liquid chromatography (HPLC) determination. ${ }^{40]}$
Qi et al. ${ }^{[41]}$ synthesized a new three-dimensional (3D) origami IIP microfluidic paper-based chip device for specific, sensitive and multiplexed detection of $\mathrm{Cu}^{2+}$ and $\mathrm{Hg}^{2+}$ ions. In this device, the surface of the paper was activated by grafting with CdTe QDs through amino processing and formation of $\mathrm{Cu}^{2+}$ or $\mathrm{Hg}^{2+} \mathrm{IIPS}$ and CdTe QDs complex that led to fluorescence quenching of QDs because the photo luminescent energy of QDs could be delivered to the complex. According to the report by Qi et al.. ${ }^{[41]}$ the device can provide quantitative information and show further extention to the detection of other metal ions for environmental monitoring and food safety field. A multi-ion imprinted polymer (MIIPs) embedded in a sol-gel matrix is reported by using $\mathrm{Hg}^{2+}, \mathrm{Cd}^{2+}, \mathrm{Ni}^{2+}$ and $\mathrm{Cu}^{2+}$ as templates and 3-aminopropyltriethoxysilane as a functional monomer and the dithizone coordination chemistry, which is enable to heavy metal removal and water pre-treatment. ${ }^{[41]} \mathrm{Xu}$ et al. reported on $\mathrm{Hg}^{2+}$-IIPs based on the thymine- $\mathrm{Hg}^{2+}$-thymine interactions for selective preconcentration of $\mathrm{Hg}^{2+}$ in water samples. ${ }^{[42]}$

\section{Reusability of the azo-based Co-IIPs and Cu-IIPs sorbents}

Reusability is an important phenomenon to evaluate the prepared polymers capability to use the sorbent in adsorption-desorption processes without significant change under the optimum condition with several times. The $\mathrm{Co}^{2+}$ ion adsorption-desorption procedure was repeated and carried out six times to test the reusability check of IIPs sorbents using the same sorbents. The same procedure was followed to check the $\mathrm{Cu}$-IIPs reusability and regeneration for $\mathrm{Cu}^{2+}$ ion. Sorbents were washed with $20 \mathrm{~mL} \mathrm{HCl}(20 \%)$ for $2 \mathrm{~h}$ to remove the corresponding metal ions $\mathrm{Co}$ (II) and $\mathrm{Cu}$ (II) completely. Furthermore, deionized water was used to rinse the sorbents to neutralize the $\mathrm{pH}$ value. Before further extraction cycle continued, the sorbents were washed and dried under vacuum at $60^{\circ} \mathrm{C}$ overnight followed by wash with deionized water.

\section{Conclusions}

Two ion imprinted polymers Co-IIP and Cu-IIP were synthesized using respective metal ion and substituted azobenzene as a complexing agent in the presence of a crosslinking agent EGDMA, methyl acrylic acid used as functional monomer and benzoyl peroxide as an initiator. For recognition and separation of corresponding ions from its mixture, leaching was performed to remove the metal ions with $20 \% \mathrm{HCl}$ solution from the template after the polymerization. The maximum sorption ability of the Co-IIPs and Cu-IIPs were found to be 95.4 and 
$103.0 \mathrm{mg} \cdot \mathrm{g}^{-1}$ of $\mathrm{Co}$ and $\mathrm{Cu}$ at $\mathrm{pH} 5$, respectively. We also investigated the metal ions binding capacity using the imprinted and non-imprinted polymers and observed that the amount of metal ions bound in the case of imprinted polymer is higher than that of non-imprinted polymer. The binding of metal ions is dependent on $\mathrm{pH}$, the adsorption values increase with increase in $\mathrm{pH}$, and a saturation value is obtained at $\mathrm{pH} 5$ to 6 . The metal ion rebinding studies of $\mathrm{Co}(\mathrm{II})$ and $\mathrm{Cu}(\mathrm{II})$ ion imprinted polymers supported that $\mathrm{Co}$ (II) and $\mathrm{Cu}$ (II)-IIPs showed specific rebinding of $\mathrm{Co}(\mathrm{II})$ and $\mathrm{Cu}(\mathrm{II})$ ions, respectively. The $\mathrm{Co}(\mathrm{II})$ and $\mathrm{Cu}(\mathrm{II})$ ions are selectively bound from its mixture with presence of bivalent cations such as $\mathrm{Ni}(\mathrm{II}), \mathrm{Zn}(\mathrm{II}), \mathrm{Cd}(\mathrm{II})$ and trivalent cations such as $\mathrm{La}$ (III), $\mathrm{Ce}(\mathrm{III})$ and $\operatorname{Pr}(\mathrm{III})$ ions. The obtained results from the studied system proved the importance of tailoring metal ion imprinted system in the recognition and removal of metal ions from the mixture. The sorbent can be used to remove or separate $\mathrm{Co}(\mathrm{II})$ and $\mathrm{Cu}(\mathrm{II})$ ions in various agricultural products and water. Moreover, the obtain results would be very useful for human and environmental issue.

\section{Acknowledgement}

This research work was supported by the University Malaysia Sabah (No. SBK0260-ST-2016) and the DSS scholarship scheme, University Malaysia Pahang.

\section{References}

[1] Andersson, L. I. J. Chromatogr. B 2000, 745, 3.

[2] Haupt, K.; Mosbach, K. Chem. Rev. 2000, 100, 2495.

[3] Sellergren, B. Angew. Chem. Int. Ed. Eng. 2000, 39, 103.

[4] Wulff, G. Chem. Rev. 2002, 102, 1.

[5] Mathew-Krotz, J.; Shea, K. J. Am. Chem. Soc. 1996, 118, 8154.

[6] Piletsky, S. A.; Panasyuk, T. L.; Piletskaya, E. V.; Nicholls, I. A.; Ulbricht, M. J. Membr. Sci. 1999, 57, 263.

[7] Duffy, D. J.; Das, K.; Hsu, S. L.; Penelle, J.; Rotello, V. M.; Stidham, H. D. J. Am. Chem. Soc. 2002, 124, 8290.

[8] Wulff, G. Chem. Int. Ed. Eng. 1995, 34, 1812.

[9] Masqueè, N.; Marceè, R. M.; Borrul, F. Trends Anal. Chem. 2001, $20,477$.

[10] Haupt, K. Anal. Chem. 2003, 75, 376A.

[11] Haupt, K.; Mosbach, K. Chem. Rev. 2000, 100, 2495.

[12] Rao, T. P.; Kala, R.; Daniel, S. Anal. Chim. Acta 2006, 578, 105.

[13] Garcia, R.; Pinel, C.; Madic, C.; Lemaire, M. Tetrahedron Lett. 1998, 39, 8651.

[14] Rao, T. P, Daniel, S.; Gladis, J. M. Trends. Anal. Chem. 2004, 23, 28.

[15] Nicholls, I. A.; Rosengren, J. P. Bioseparation 2001, 10, 301.

[16] Liu, H.; Kong, D. L.; Sun, W.; Li, Q. S.; Zhou, Z. Y. Chem. Eng. J. 2016, 303, 348.

[17] Zhan, Y. C.; Luo, X. B.; Ni, S. S.; Huang, Y. N.; Tu, X. M.; Luo, S. L. Ind. Eng. Chem. Res. 2011, 50, 6355.

[18] Cau, X.; Li, J.; Zhang, Z.; Yang, F.; Dong, R.; Chen, L. ACS Appl. Mater. Interfaces 2014, 6, 305.
[19] Pan, J. M.; Zeng, J.; Cao, Q.; Gao, H.; Gen, Y.; Peng, Y.; Dai, X.; Yan, Y. Chem. Eng. J. 2016, 284, 1361.

[20] Chen, L.; Ji, T.; Brisbin, L.; Zhu, J. H. ACS Appl. Mater. Interfaces 2015, 7, 12230.

[21] Qi, P. F.; Pichler, T. Langmuir 2014, 30, 11110.

[22] Abbas, M.; Kaddour, S.; Trari, M. J. Ind. Eng. Chem. 2014, 20, 745.

[23] Uzun-Karatepe, A.; Soylak, M.; Elci, L. Anal. Lett. 2002, 35, 2363.

[24] Awual, M. R.; Yaita, T.; Okamoto, Y. Sens. Actuators: B 2014, 203, 71.

[25] Aurelia, P.; Irina, C.; Dana, V.; Mirela, D.; Mircea, R. Rev. Chim. (Bucharest) 2015, 66, 1819.

[26] Soylak, M.; Elci, L.; Dogan, M. Anal. Lett. 2006, 30, 631.

[27] Wellens, S.; Thijs, B.; Binnemans, K. Green Chem. 2012, 14 , 1657.

[28] Narin, I.; Soylak, M. Anal. Chim. Acta 2003, 493, 205.

[29] Gogada, R.; Singh, S. S.; Lunavat, S. K.; Pamarth, M. M.; Rodrigue, I.; Vadivelu, A. B.; Phanithi, P. B.; Gopala, V.; Apte, S. K. Appl. Microbiol. Biotchnol. 2015, 99, 9203.

[30] Farzaneh, S.; Asadi, E.; Abdouss, M.; Barghi-Lish, A.; Azodi-Deilami, S.; Khonakdar, H. A.; Gharghabi, M. RSC Adv. 2015, 5, 9154.

[31] Javanbakht, M.; Attaran, A. M.; Namjumanesh, M. H.; EsfandyariManesh, M.; Akbari-Adergani, B. J. Chromatogr. B 2010, 878, 1700.

[32] Yusoff, M. M.; Mostapa, N. R. N.; Sarkar, M. S.; Biswas, T. K.; Rahman, M. L.; Arshad, S. E.; Sarjadi, M. S.; Kulkarn, A. D. J. Rare Earths 2017, 35, 177.

[33] Gao, B.; Zhang, Y.; Xu, Y. Hydrometal 2014, 150, 83

[34] Andac, M.; Özyapl, E.; Senel, S.; Say, R.; Denizli, A. Ind. Eng. Chem. Res. 2006, 45, 1780.

[35] Solaiman, E. M.; Mahmoud, M. E.; Ahmed, S. A. Talanta 2001, 54, 243.

[36] Zhang, Z.; Li, J.; Song, X.; Ma, J.; Chen, L. RSC Adv. 2014, 4 , 46444.

[37] Fu, J; Chen, L.; Li, J.; Zhang, Z. J. Mater. Chem. A 2015, 3, 13598.

[38] Chen, L.; Wang, X.; Lu, W.; Wu, X.; Li, J. Chem. Soc. Rev. 2016 45, 2137.

[39] Wang, L.; Li, J.; Wang, J.; Guo, X.; Wang, X.; Choo, J.; Chen, L. J. Coll. Interface Sci. 2019, 541, 376.

[40] Bagheri, A. R.; Arabi, M.; Ghaedi, M.; Ostovan, A.; Wang, X.; Li, J.; Chen, L. Talanta 2019, 195, 390.

[41] Qi, J.; Li, B.; Wang, X.; Zhang, Z.; Wang, Z.; Han, J; Chen, L. Sens. Actuators: B 2017, 251, 224

[42] Fu, J.; Wang, X.; Li, J.; Ding, Y.; Chen, L. RSC Adv. 2016, 6, 44087.

[43] Xu, S.; Chen, L.; Li, J.; Guan, Y; Lu, H. J. Hazard. Mater. 2012, 237, 347. 